\title{
Glaucoma and CNS. Comparison of fMRI results in high tension and normal tension glaucoma
}

\author{
Jan Lestak ${ }^{\mathrm{a}, \mathrm{b}, \mathrm{c}}$, Jaroslav Tintera ${ }^{\mathrm{a}}$, Zuzana Svata ${ }^{\mathrm{a}}$, Lukas Ettler ${ }^{\mathrm{a}}$, Pavel Rozsival ${ }^{\mathrm{c}}$
}

\begin{abstract}
Aim. The objective of our work was to determine whether there is a difference in fMRI activation between patients with high tension glaucoma (HTG) and those with normal tension glaucoma (NTG).

Method. The sample consisted of eight patients with different stages of high tension glaucoma (3 females aged 41-65 and 5 males aged 40-73 years) and eight patients, also with different stages of normal tension glaucoma ( 6 females aged 53-70 and 2 males aged 40-52 years). The control group consisted of eight healthy subjects ( 3 females aged 23-46 and 5 males aged 23-65 years). All underwent complete ophthalmological examination, including visual field, colour vision, and electrophysiological functions. The results were compared with $\mathrm{fMRI}$ images after stimulation with black/white (BW) and blue/yellow (BY) checkerboard and then statistically processed.

Results. The authors analyzed the results of published studies on high tension versus normal tension glaucoma in the images obtained by fMRI. They concluded on the basis of electrophysiological examinations that in high tension glaucoma, damage of the whole visual pathway occurs, starting from retinal ganglion cells up to the visual cortex. In normal tension glaucoma the response of ganglion cells is relatively normal. The pathology is found mainly in the visual pathway. For this reason, the authors carried out fMRI examinations in high tension glaucoma patients and patients with normal tension glaucoma. They found that advancing stages of high tension glaucoma cause progression of fMRI activity decrease. These relations were not observed in normal tension glaucoma cases. Similarly, in high tension glaucoma on $\mathrm{fMRI}$ examination to yellow/blue stimuli, the fMRI activity decrease was found to be greater than that to black/white stimulation. No similar effect was observed in normal tension glaucoma.
\end{abstract}

Conclusion. Normal tension glaucoma is, from the etiopathogenetical view, a different disease than high tension glaucoma.

Key words: high tension glaucoma, normal tension glaucoma, CNS, fMRI, visual field sensitivity

Received: October 29, 2012; Accepted: May 20, 2013; Available online: June 4, 2013

http://dx.doi.org/10.5507/bp.2013.038

${ }^{a}$ Eye department of the Clinic JL, V Hurkach 1296/10, Prague, Czech Republic

${ }^{b}$ Department of Medicine and Humanities, Faculty of Biomedical Engineering, Czech Technical University in Prague, Prague

'Department of Ophthalmology, Faculty of Medicine in Hradec Kralove, Charles University in Prague and University Hospital Hradec Kralove, Hradec Kralove

Corresponding author: Jan Lestak, e-mail: lestak@seznam.cz

\section{INTRODUCTION}

HTG is still being defined as a chronic progressive neuropathy with cupping and atrophy of the optic disc and consequent visual field changes. The formulation does not reflect current knowledge and should be corrected. The latest concept of glaucoma defines it as a condition where progressive loss of retinal ganglion cells and their axons is manifested by visual field changes, atrophy and cupping of the optic disc. However, even this definition, emphasizing the retinal ganglion cells damage occurring before the damage to retinal axons is not complete because it does not mention the concurrent ganglion cells damage of visual subcortex and cortex.

The NTG compared to HTG is known to be different in some aspects: Apart from the intraocular pressure, it is the nature of visual field changes that affect more the centre and have a more pronounced decrease in sensitivity ${ }^{1-3}$, the nerve fibres loss affects more the centre of the retina and has a focal nature ${ }^{4}$, larger and deeper cupping with a thinner lamina cribrosa ${ }^{5,6}$, vasospasms ${ }^{7}$, night systemic hy- potension conditions, reduced ocular pulse amplitude and ocular perfuse pressure fluctuations ${ }^{8-10}$, narrower retinal veins, lately even worse haemorrheological blood properties $^{11-13}$ and others.

The pathophysiological mechanism of retinal damage in HTG is not yet known. Epidemiological studies have shown that elevated intraocular pressure is the most frequent parameter detected in human glaucoma ${ }^{14}$. Characteristic pathological retinal change in glaucoma is the ganglion cells loss. Whether the selective ganglion cells loss is a direct effect of intraocular pressure, pressure-induced ischemia or some other mechanism, remains at the level of controversial discussions. Any mechanism of glaucoma-induced retinal ganglion cell damage occurs secondarily after the damage of their axons that lead to the subcortex and cortex centres.

Much information in discussions about damage to retinal ganglion cells and their axons has been brought by the work of Naskar et al. ${ }^{15}$. The authors used a rat eye to study experimental HTG, in which they cauterized three of four episcleral veins of the eye surface and stained retrogradely 
retinal ganglion cells with fluorogold dye. After episcleral veins cauterization the intraocular pressure increased 1.6 times and remained elevated at values of $25.3+/-2 \mathrm{mmHg}$ for a period of three months after the surgery. Number of retinal ganglion cells decreased in 2.5 months by $40 \%$. The first changes in the optic disc meaning the origin of cupping appeared after two months. The authors presume that changes at the level of ganglion cells occur earlier than changes in their axons, and conclude that in this experimental model of glaucoma the apoptosis of retinal ganglion cells was due to the block of axoplasmatic transport.

Weber et al. ${ }^{16}$ dealt with morphological changes in lateral geniculate nucleus (LGN). Increased intraocular pressure in monkeys influenced not only the size, density and number of neurons in LGN but the LGN volume as well. Increased intraocular pressure (higher than $40 \mathrm{mmHg}$ ) induced cellular changes earlier than medium intraocular pressure, but a comparable damage was registered even at medium pressure $(28-37 \mathrm{mmHg})$. High intraocular pressure had a greater influence on the magnocellular than the parvocellular neurons (59\% vs. 31\%). The degree of shrinking of LGN itself (after volume correction) indicated that the magnocellular ganglion cell loss is 4 times higher than the parvocellular one (38\% vs. $10 \%)$.

Similarly, Yücel et al. ${ }^{17}$ tried to find whether there is atrophy of LGN magnocellular and parvocellular neurons, the fibres which are leading to the visual cortex, and to compare the degree of neuronal atrophy of magnocellular layers with the parvocellular ones. Experiments were carried out in seven monkeys (cynomolgus) with unilateral experimentally induced glaucoma. Five monkeys of the same species were the control group. Both magnocelullar and parvocellular neurons - LGN- were examined, and following that, immunochemical examination of neurons in visual cortex was carried out. Average cross-sectional area in magnocellular and parvocellular layers were, compared with controls, significantly lower - by $28 \%, 37 \%$, or $45 \%$. The authors concluded that the LGN neurons that continue to the visual cortex, are subject to significant reduction in size in glaucoma, parvocelullar neurons being thus more affected than the magnocellular ones.

Crawford et al. ${ }^{18}$ noted in monkeys with unilateral experimental glaucoma an alteration of afferent inputs to V1 primary centre related to changes in LGN. Experimental glaucoma in monkeys affects the metabolism in both parts of geniculocortical afferent pathways and the dendritic tree of magnocellular neurons is subject to changes sooner than the parvocelullar neurons ${ }^{19,20}$.

Crawford et al. ${ }^{18,21}$ proved later that experimental HTG reduces the reactivity of cytochrome oxidase both in magnocellular and parvocellular cells.

The above described experimental models can be similar to a patient 's condition with secondary glaucoma after branch retinal vein occlusion. PET (positron emission tomography) finding in that patient is shown in Fig. 1. Simultaneously, a perimetric study shown in Fig. 2 was carried out at the same patient as well.

The finding of the perfusion deficit on the FDG-PET scans motivated us to further investigation of visual cortex in patients with glaucoma disease.

We tried to determine in this work, whether there is a correlation between visual field changes in HTG and NTG and changes in functional MRI in the visual cortex.
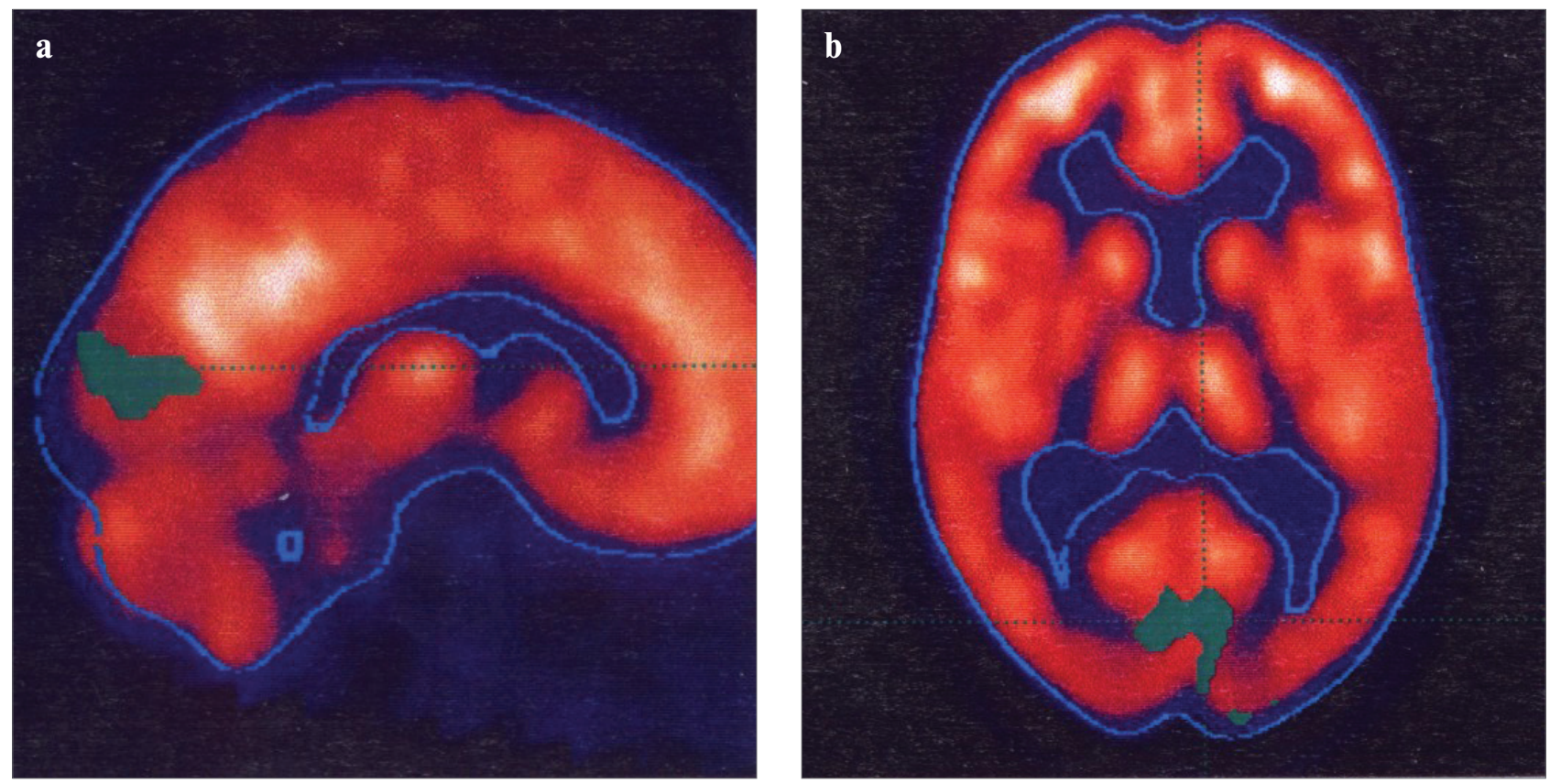

Fig. 1. PET examination in the patient with secondary glaucoma (48-year-old male. VA RE 0.05, VA LE 1.0, on the right after branch retinal vein occlusion, $\mathrm{C} / \mathrm{D}=1.0$ bilaterally).The patient was examined in 2001 after application of fluorodeoxyglucose that showed perfusion deficit in visual cortex - green colour, a) sagittal section, b) axial section. 

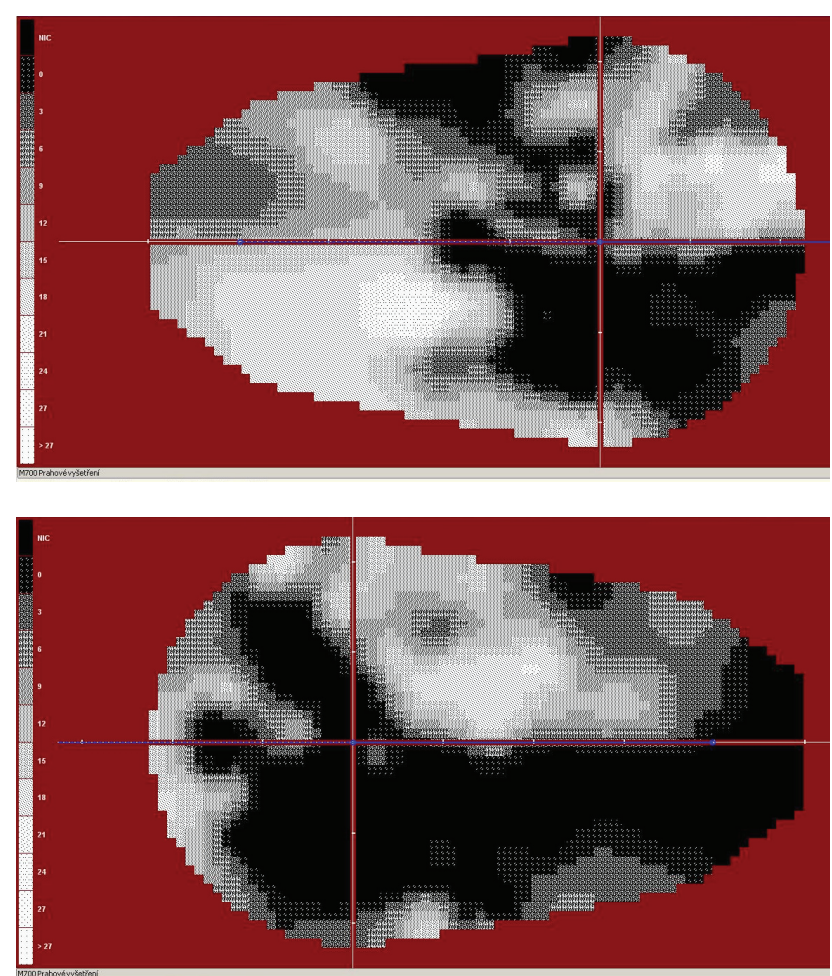

Fig. 2. Above - the visual field of the right eye, below - the visual field of the left eye in the same patient as in Figure 1. The visual field was examined in 2001. Pattern defect on the right 15.55, on the left 18.66 .

\section{METHODS}

\section{Groups of examined patients}

In our study we worked with two groups of glaucoma patients and one control group of healthy persons. The first group consisted of 8 patients with different stages of HTG ( 3 females aged $41-65$ and 5 males aged $40-$ $73)$. The second group with NTG consisted of 8 patients ( 6 females aged $53-70$ and 2 males aged $40-52$ years). All examinations were performed in 2011.
Both the groups were compared with a group of 8 healthy people ( 3 females aged $23-46$ and 5 males aged $23-65)$.

\section{Functional MRI}

All measurements of functional MR imaging (fMRI) were performed on a Philips Achieva TX SERIES with magnetic field strength of 3 Tesla. A standard 8-channel SENSE head RF coil was used for scanning. Optical stimulation for fMRI was performed with a commercially available ESys (InVivo) stimulus system.

The measured volume consisted of 39 contiguous slices with thickness of $2 \mathrm{~mm}$ and the size of the measured voxel (spatial resolution) was $2 \times 2 \times 2 \mathrm{~mm}$ (FOV= $208 \times$ $208 \mathrm{~mm}$, matrix $104 \times 104$, reconstruction matrix $128 \mathrm{x}$ 128, SENSE factor of 1.8). Two fMRI measurements were performed for each examination with different types of optical stimulation: In the active phase of the first measurement, the subjects were exposed to alternations of black/white (BW) checkerboard pattern (see Fig. 3a), while yellow/blue (YB) checkerboard pattern alternations were used in the second measurement (see Fig. 3b). This alternation was done in the form of colour inversion with a frequency of $2 \mathrm{~Hz}$. During the resting phase, the subjects were shown a static cross hair placed in the middle of the visual field. Each measurement consisted of a sequence with five 30 -second periods of active phase (10 dynamic scans) and five resting periods of the same duration. Therefore, each measurement consisted of a total of 100 dynamic scans and lasted $5 \mathrm{~min}$.

The fMRI evaluation was performed in SPM8 software. During the pre-processing, the data were corrected for motion (realignment) and time shift of the slices (slice timing) followed by smoothing using Gaussian filter with FWHM of $6 \times 6 \times 6 \mathrm{~mm}$ and finally normalized into the MNI-152 space. A general linear model with canonical HRF (hemodynamic response function) applied to the stimulation periods was used for statistical evaluation of all subjects. Individual statistical maps were thresholded at the level of $P=0.05$ with FWE correction and the mini-
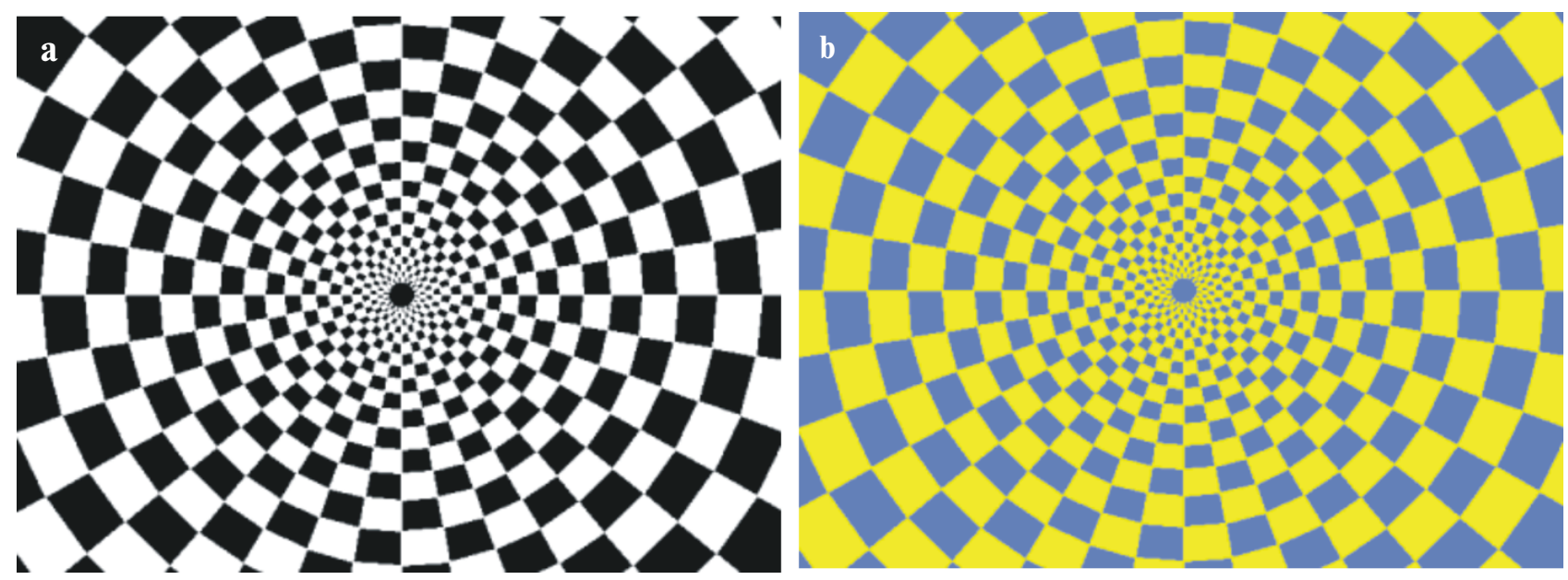

Fig. 3. Stimulation by black/white (BW) chequered pattern (a) and yellow/blue (YB) chequered pattern (b). During the stimulation, the chequered pattern was alternated with its inversion with a frequency of $2 \mathrm{~Hz}$. 
mum cluster size of 10 voxels. The statistical maps of $\mathrm{BW}>\mathrm{YB}$ and $\mathrm{YB}>\mathrm{BW}$ differences were thresholded at the level of $P=0.001$, without correction, and the minimum cluster size of 10 voxels.

\section{Ophthalmological examination}

To the complete ophthalmological examination the test of visual field in the quick threshold program on the device Medmont M700 Automated Perimeter was added. The sum of sensitivity in the homolateral halves of visual fields - HH VF (in the range from 0 - 22 degrees) was then used to compare it with the extent of contralateral fMRI activity of visual cortex.

To investigate colour perception in our patients with normal tension glaucoma we used the Lanthony 15 -Hue test and the Ishihara test.

\section{Statistics}

For data obtained in the form of the number of activated voxels fMRI and values of changes in the visual cortex (the sum of sensitivity in the homolateral halves of visual fields), statistical analysis by means of non-parametric Spearman rank correlation coefficient was used.

\section{RESULTS}

Functional MRI showed activations in the visual cortex in all subjects tested. An example of a typical activation in a healthy volunteer by the black/white and yellow/ blue stimulation is shown in Fig. 4, while Fig. 5 demonstrates the decrease of activation in a patient with HTG. Conversely, no decrease in fMRI activation in a typical patient with NTG is shown in Fig. 6, and the results of testing visual fields in Fig. 7.
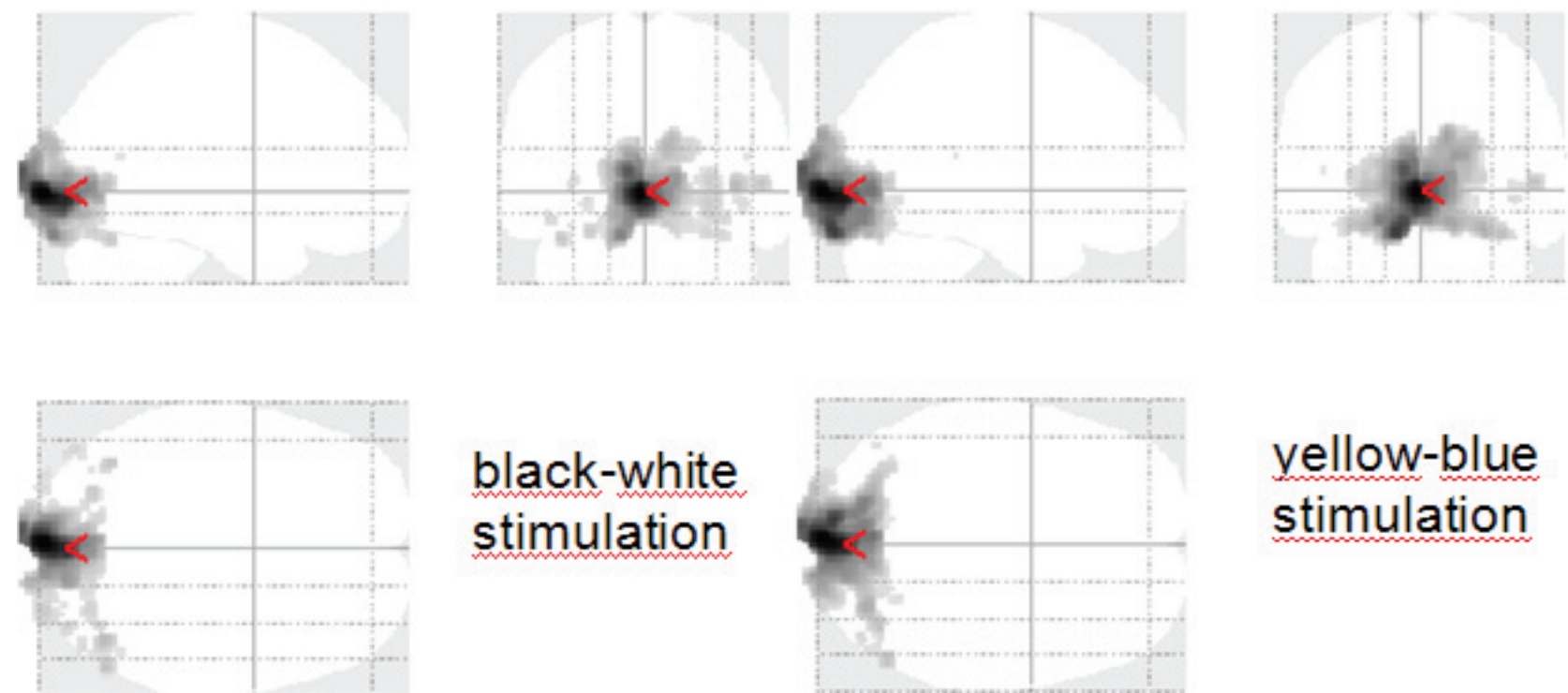

\section{black-white stimulation}
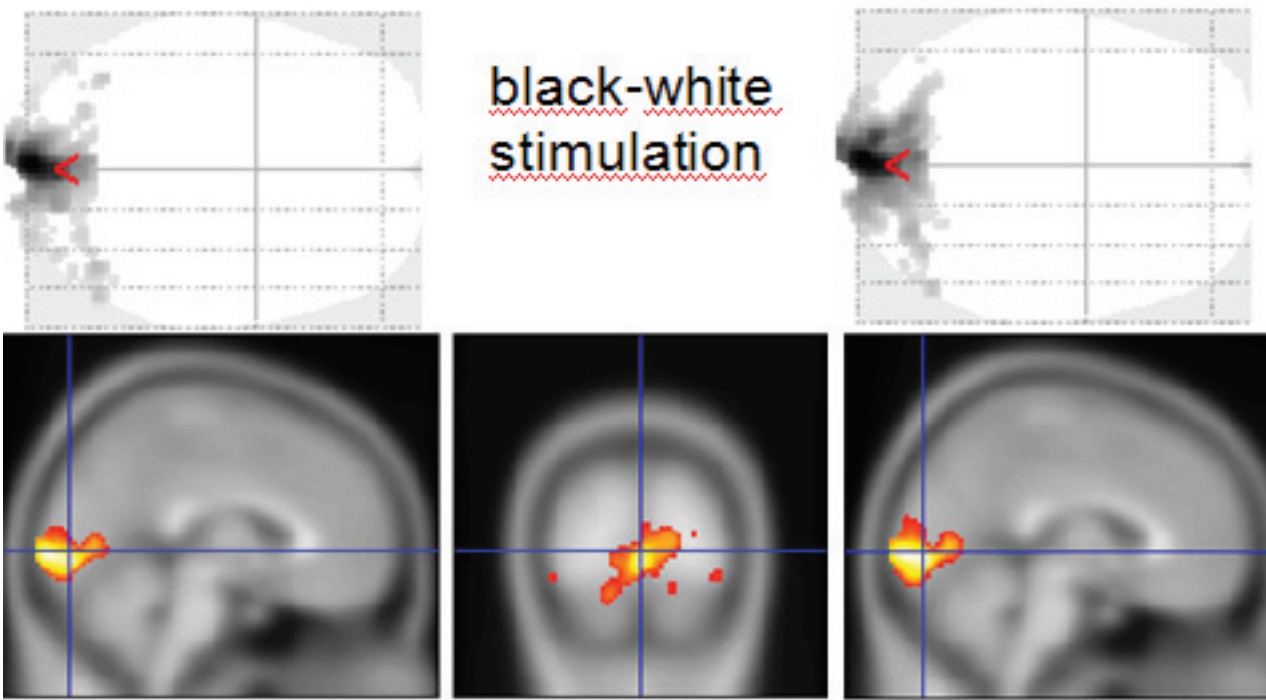

\section{yellow-blue stimulation}
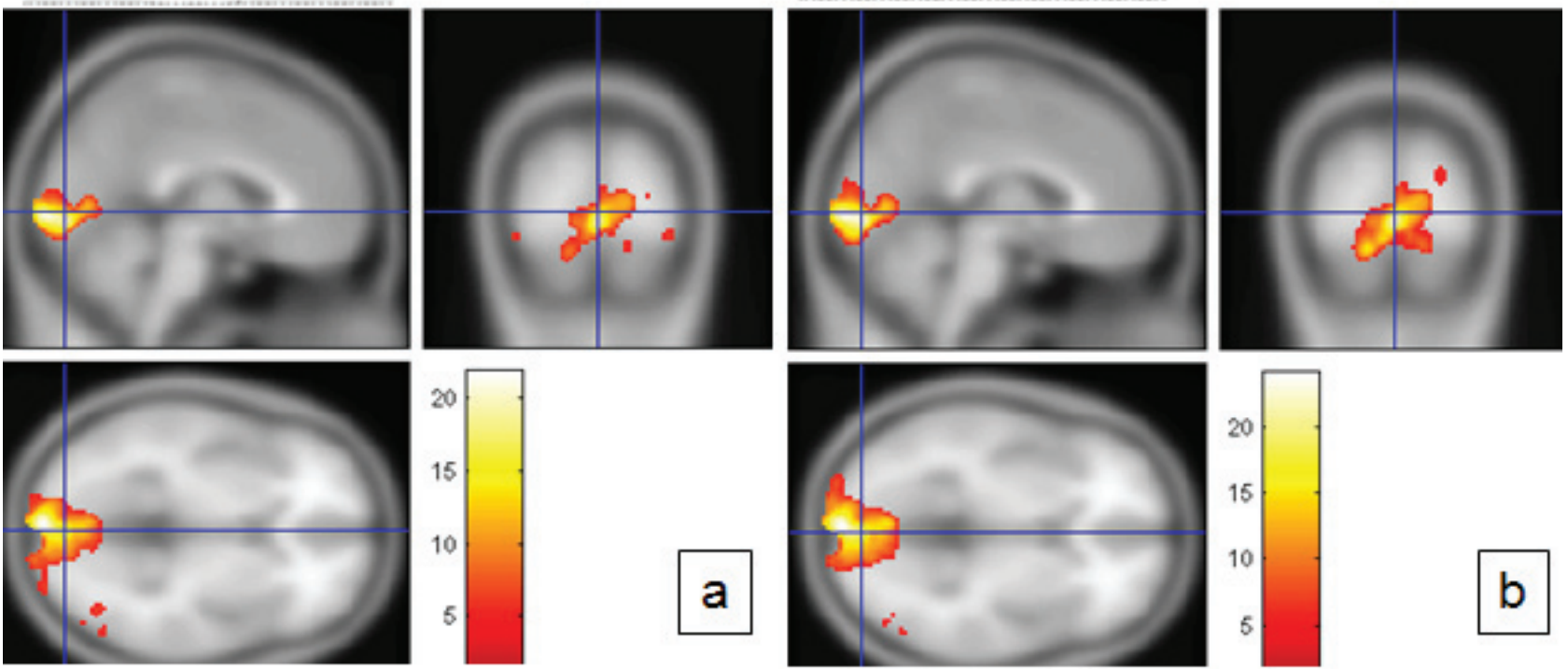

Fig. 4. Resulting fMRI images of a selected healthy subject - 56-year-old male. (a) shows the black/white checkerboard visual stimulation. (b) shows the yellow/blue checkerboard visual stimulation. Above - orthogonal projection, below - multi-planar reconstruction. 

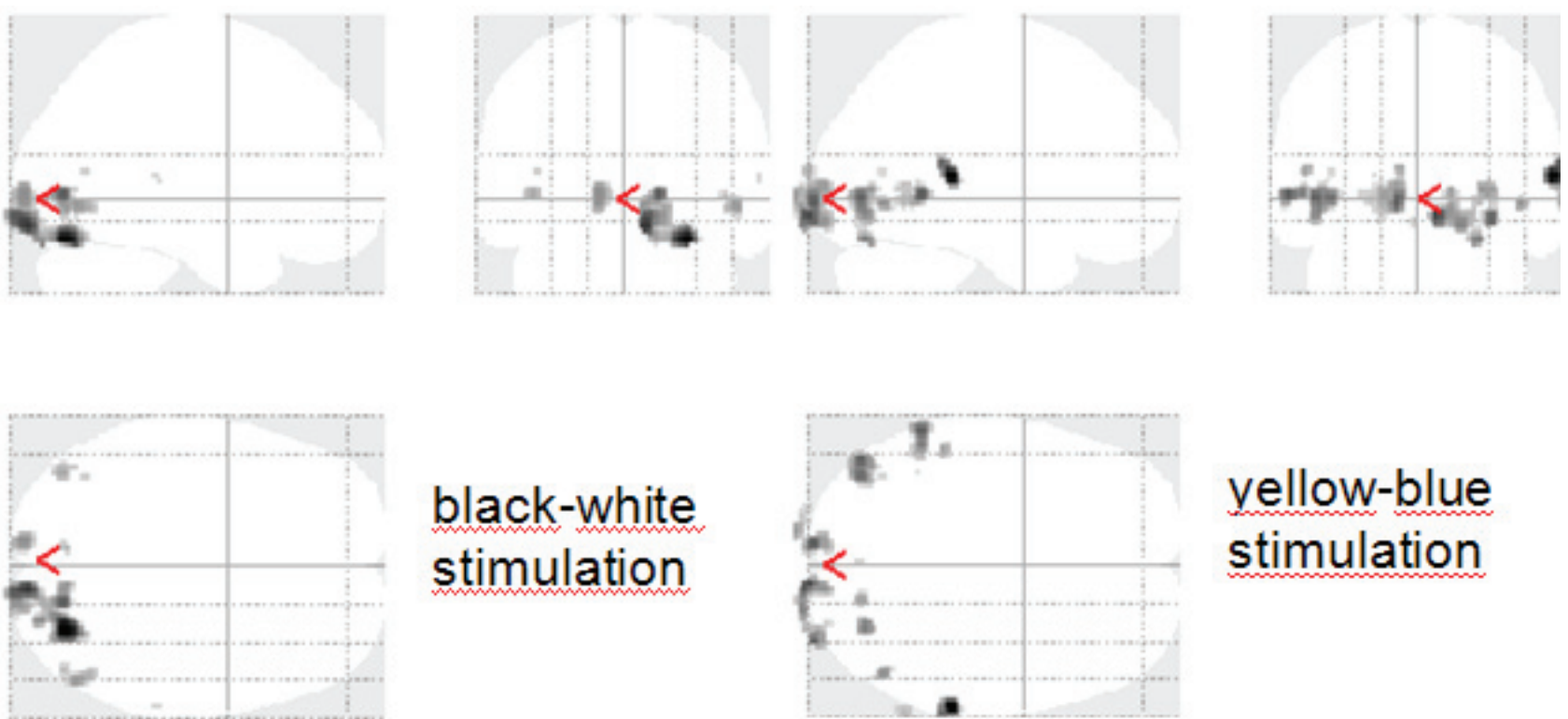

\section{black-white stimulation}
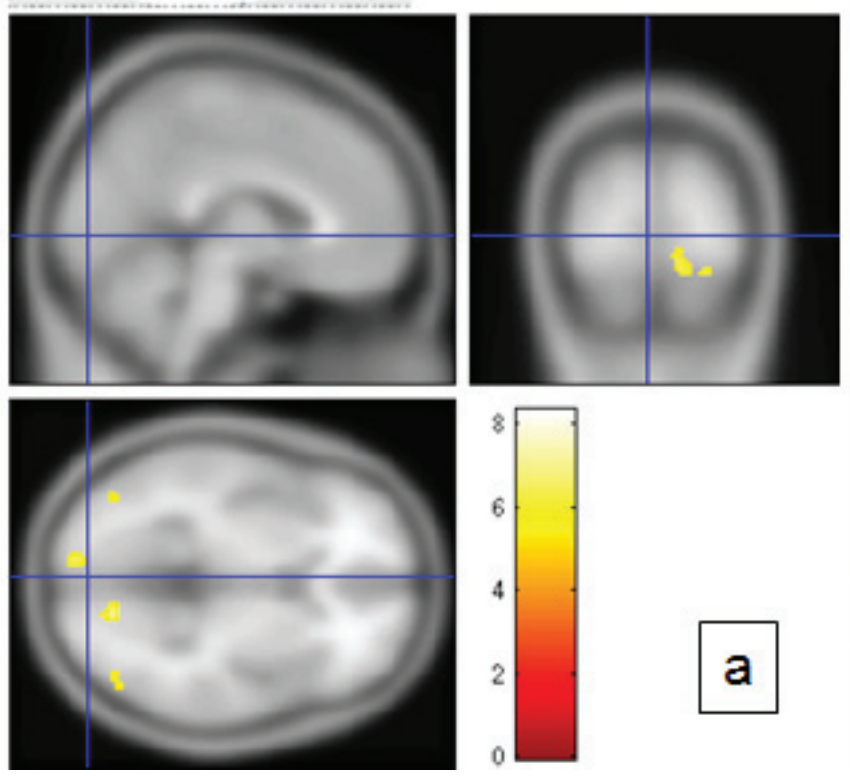

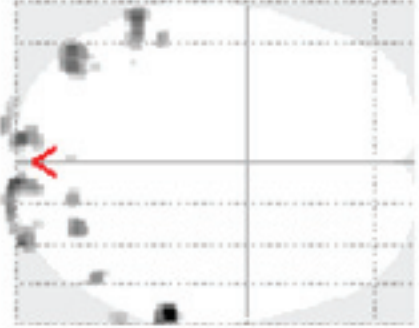

\section{yellow-blue stimulation}
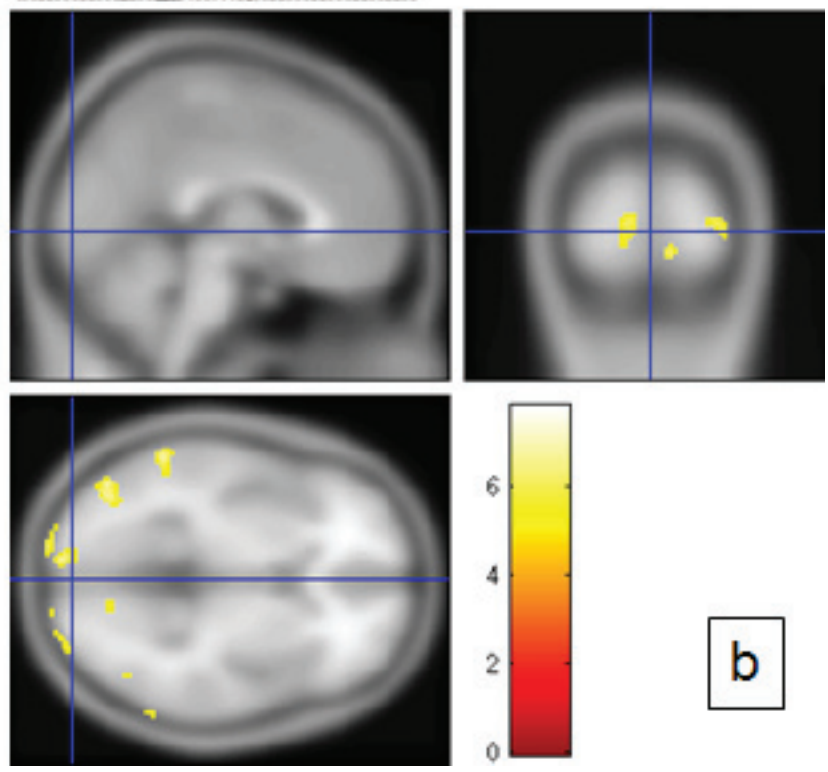

Fig. 5. Example of fMRI in a patient with HTG, whose visual field measurement is shown in Fig. 1 and 2. (a) shows the results with the black/white visual stimulation, whereas (b) with the yellow/blue stimulation. We can register a significant decrease in activity of visual cortex neurons. Above - orthogonal projection, below - multi-planar reconstruction.

The resulting activations during the optical stimulation for each subject are presented in Table 1. The values shown in the table represent the number of activated voxels in the occipital gyrus during the stimulation by black/ white (BW) and yellow/blue (YB) checkerboard patterns.

In patients with HTG, statistics using the Spearman coefficient also showed moderate correlation between visual field changes and changes in the visual cortex after the $\mathrm{BW}$ stimulation. $\mathrm{R}=0.667(P<0.05)$ or $\mathrm{R}=0.767$ $(P<0.016)\left(\right.$ ref. $\left.^{22}\right)$.

In patients with NTG, statistical analysis using the same coefficient showed a weak indirect correlation between visual field changes and changes in the visual cortex. $\mathrm{R}=-0.270(P=0.558)$, or $\mathrm{R}=-0.071(P=0.879)\left(\right.$ ref $\left.^{23}\right)$.

Average number of activated voxels during BW stimulation was 6,563 in HTG, 7,626 in NTG, and 7,462 in the control group; the extent of activation did not differ statistically in any of the groups. When activated by YB checkerboard, the activation range decreased on average to 4,282 in HTG, to 5,649 in NTG, and to 6,353 in healthy controls. Though the difference between the control group and HTG is not significant $(P=0.17)$, it suggests the possible difference in the activation pattern in HTG. Therefore, we focused on testing the difference between BW and YB stimulations.

It can be seen from the table that the difference in the magnitude of activation of the visual cortex during the BW and YB stimulation is markedly higher in the patients with high tension glaucoma than it is in the healthy controls. The mean value of the difference in the number of activated voxels using the BW vs. YB stimulation is 59\% for glaucoma patients while for the healthy controls it is 

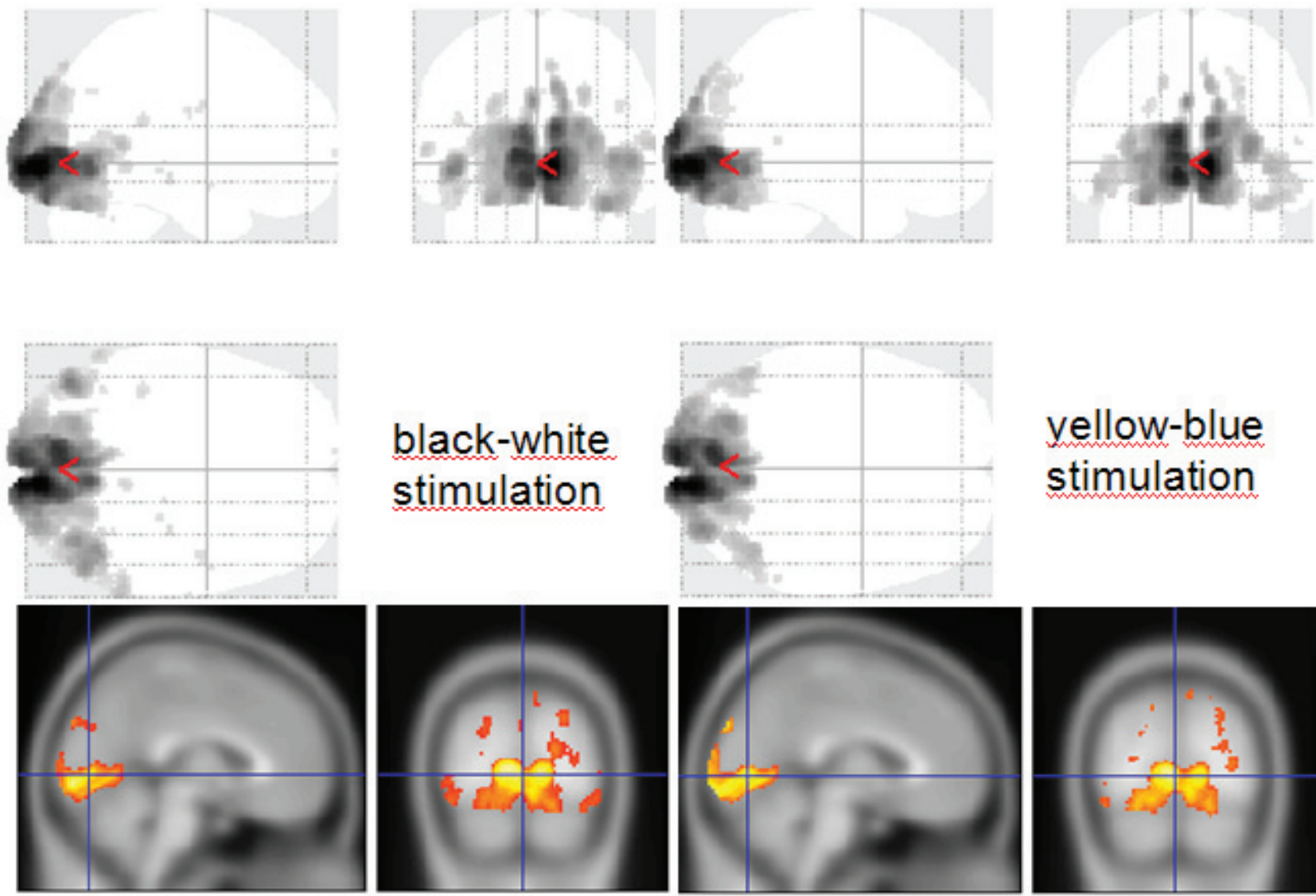

\section{black-white stimulation}

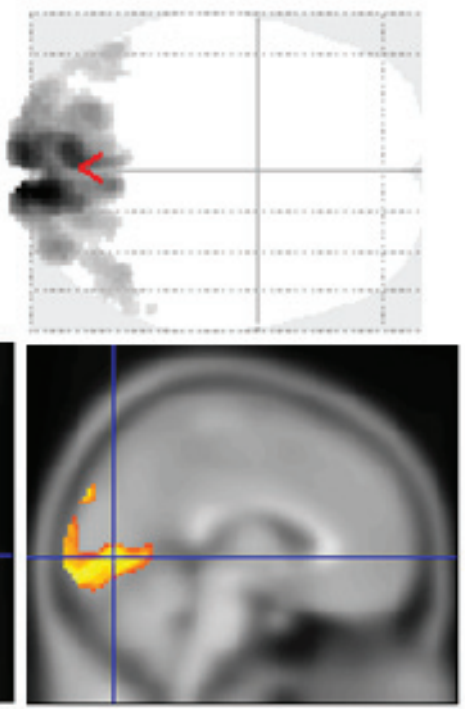

\section{yellow-blue stimulation}
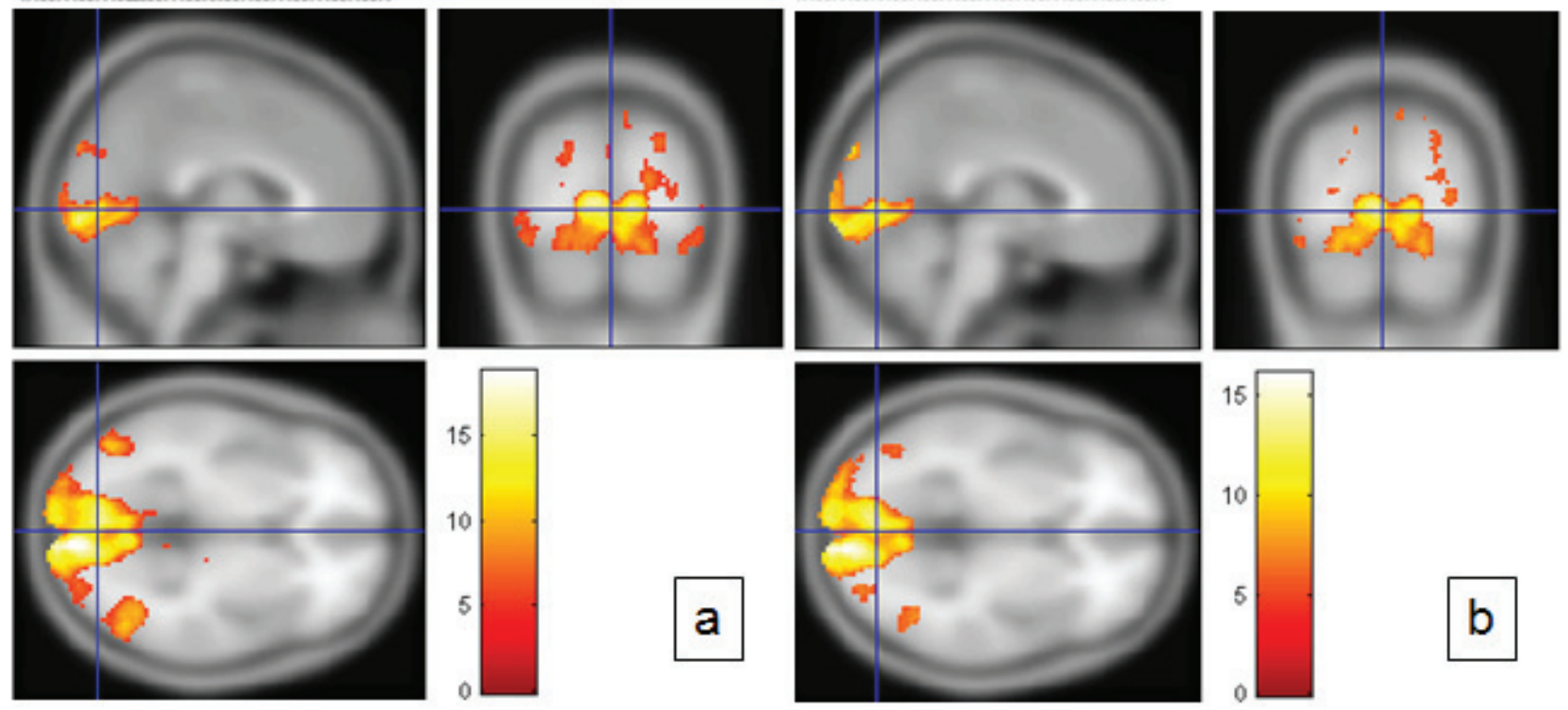

Fig. 6. Example of fMRI results with the black/white (a) and yellow/blue (b) visual stimulation in a 61-year-old female with NTG. VA: 1.0 C/D=1.0. IOP 12/12 mmHg. Above - orthogonal projection, below - multi-planar reconstruction.
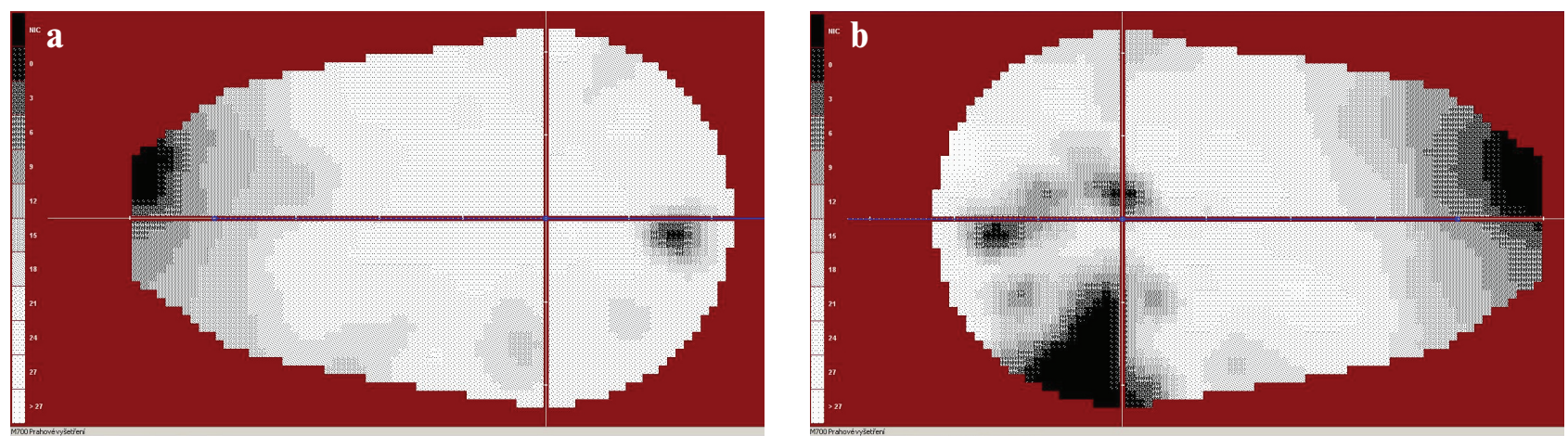

Fig. 7. (a) - right visual field (pattern defect=2.51), (b) - the left visual field of the same patient as in Figure 6 (pattern defect $=8.19$ ).

only $2 \%$. Statistical maps of $\mathrm{BW}>\mathrm{YB}$ and $\mathrm{BW}<\mathrm{YB}$ differences for the patients and controls were thresholded at an uncorrected threshold of $P=0.001$ at individual level (for each subject: $4^{\text {th }}$ and $5^{\text {th }}$ column in Table 1 ) and the numbers of voxels were statistically compared between all groups using t-test. While the BW>YB difference between the control group and the patients differed by the statistically significant 1,606 voxels $(P=0.039)$, no difference was found for $\mathrm{BW}<\mathrm{YB}(P=0.18)$. 
Table 1. The range of activations represented by the number of statistically significant voxels during the stimulation by black/ white (BW) and yellow/blue (YB) chequered patterns. The next two columns show the statistically significant differences between BW and YB stimulations, expressed again by the number of voxels (with tested hypothesis being BW $>$ YB, YB $>B W$ resp.).

The last two columns show the percentage difference in the number of activated voxels of the statistical difference.

\begin{tabular}{|c|c|c|c|c|c|c|}
\hline Subject & BW & YB & $\mathrm{BW}>\mathrm{YB}$ & $\mathrm{YB}>\mathrm{BW}$ & $\frac{2(\mathrm{BW}-\mathrm{YB})}{(\mathrm{BW}+\mathrm{YB})}$ & $\frac{2(\mathrm{YB}-\mathrm{BW})}{(\mathrm{BW}+\mathrm{YB})}$ \\
\hline HTG Patient 1 & 7400 & 5900 & 720 & 97 & $11 \%$ & $1 \%$ \\
\hline HTG Patient 2 & 3700 & 3500 & 52 & 52 & $1 \%$ & $1 \%$ \\
\hline HTG Patient 3 & 4400 & 1100 & 5200 & 300 & $189 \%$ & $11 \%$ \\
\hline HTG Patient 4 & 12100 & 10900 & 620 & 400 & $5 \%$ & $3 \%$ \\
\hline HTG Patient 5 & 8500 & 3600 & 2640 & 0 & $44 \%$ & $0 \%$ \\
\hline HTG Patient 6 & 3800 & 60 & 4080 & 386 & $211 \%$ & $10 \%$ \\
\hline HTG Patient 7 & 8400 & 6900 & 550 & 0 & $7 \%$ & $0 \%$ \\
\hline HTG Patient 8 & 4200 & 2300 & 0 & 0 & $0 \%$ & $0 \%$ \\
\hline NTG Patient 1 & 10730 & 8050 & 1400 & 0 & $15 \%$ & $0 \%$ \\
\hline NTG Patient 2 & 8730 & 5770 & 760 & 0 & $10 \%$ & $0 \%$ \\
\hline NTG Patient 3 & 10375 & 5300 & 610 & 0 & $8 \%$ & $0 \%$ \\
\hline NTG Patient 4 & 10160 & 8050 & 390 & 0 & $4 \%$ & $0 \%$ \\
\hline NTG Patient 5 & 3730 & 3200 & 0 & 0 & $0 \%$ & $0 \%$ \\
\hline NTG Patient 6 & 5560 & 4670 & 0 & 430 & $0 \%$ & $8 \%$ \\
\hline NTG Patient 7 & 3590 & 2510 & 180 & 0 & $6 \%$ & $0 \%$ \\
\hline NTG Patient 8 & 8130 & 7650 & 220 & 150 & $3 \%$ & $2 \%$ \\
\hline Control 1 & 3800 & 3200 & 0 & 0 & $0 \%$ & $0 \%$ \\
\hline Control 2 & 8300 & 6600 & 39 & 0 & $1 \%$ & $0 \%$ \\
\hline Control 3 & 3900 & 5800 & 170 & 110 & $4 \%$ & $2 \%$ \\
\hline Control 4 & 17700 & 10600 & 550 & 0 & $4 \%$ & $0 \%$ \\
\hline Control 5 & 6900 & 6900 & 12 & 35 & $0 \%$ & $1 \%$ \\
\hline Control 6 & 7750 & 4550 & 46 & 0 & $1 \%$ & $0 \%$ \\
\hline Control 7 & 7150 & 6980 & 8 & 39 & $0 \%$ & $1 \%$ \\
\hline Control 8 & 4200 & 6200 & 190 & 580 & $4 \%$ & $11 \%$ \\
\hline
\end{tabular}

On the contrary, an average difference between BW and YB in patients with normal tension glaucoma was only $6 \%$ (in control group $2 \%$ ). However, numbers of voxels in differential maps did not differ significantly between both the groups - neither for BW>YB (318 voxels, $P=0.098$ ) or for $\mathrm{YB}>\mathrm{BW}$ (23 voxels, $P=0.799$ ).

\section{DISCUSSION}

Studies dealing with functional magnetic resonance imaging in HTG are not many ${ }^{24-26}$. They all described changes in the area of visual cortex in human glaucoma. In our study we tried to demonstrate in patients with various visual field changes not only the damage to the central nervous system (CNS) in glaucoma, but also the degree of functional changes in the visual cortex in response to visual field changes.

An animal model of glaucoma suggests that retinal ganglion cells affect adversely the cells V1 by transsynaptic degeneration. Transsynaptic degeneration may play a role in the animal model of glaucoma as well ${ }^{27,28}$. Only few reports describe this fact in humans. Death of retinal ganglion cells can quickly start a cascade of events along retinocortical pathways that have neurochemical ${ }^{19}$, metabolic $^{18,21}$, functional ${ }^{29}$ and neuropathological consequences for corpus geniculatum laterale and V1. Neurons loss and final shrinking of them may occur as well $16,17,30,31$.

It is necessary to emphasize that measurement of changes in neuronal activity using fMRI does not provide a direct evidence of glaucoma-linked neurodegeneration in CGL or V1. Functional changes in neuronal activity of neuronal disorders can be independent of structural changes in neurons/axons in the CNS and vice versa. For example, current fMRI studies found that neuronal activity in the cortical representation of the fovea centralis, persists despite a clear retinal macular pathology with loss of foveal vision ${ }^{32,33}$. Cell death in glaucoma is not an important limit of transsynaptic degeneration associated with a glaucoma eye.

Visual field changes in HTG arise as a result of loss of ganglion cells and their axons throughout the visual 
system. Qing et al. ${ }^{26}$ found a negative correlation between visual field changes (they evaluated PSD) and fMRI activations. This negative correlation means that if the values of PSD increase with the visual field changes, then the scope of fMRI activation decreases. In our group, where we compared the sum of sensitivity in the homolateral halves of visual field, the value of sensitivity in the visual field decreased with the progression of the disease, similarly as the extent of fMRI activation; in other words, we noted a positive correlation. The correlation coefficient between right $\mathrm{HH} \mathrm{VF}$ and fMRI activations on the left was $0.667(P<0.05)$. The correlation coefficient between the left HH VF and fMRI activations on the right was $0.767(P<0.016)$.

Based on our results, we presume that the decrease in fMRI activation is not due to a vascularisation impairment of the affected area, but is rather due to changes in neurovascular coupling at oxygen extraction by decreased number of surviving neurons. This so-called transsynaptic degeneration is espoused by Duncan et al. ${ }^{24,25}$ as well.

In normal tension glaucoma there is no direct retinal ganglion cell damage ${ }^{34}$. The pathology is mainly in the visual pathway. Visual field changes, caused by normal tension glaucoma, probably arise due to the loss of retinal ganglion cells, and this decrease causes the cupping. In HTG, the decrease of ganglion cells in the retina occurs in the initial stages. Therefore, the nature of visual field changes in both diagnostic groups differs as well.

In our group, where the sum of sensitivity in the homolateral halves of visual field was compared with fMRI activation, we did not statistically demonstrate any significant relationship.

The resulting correlation coefficient between the right halves of visual fields and the scope of fMRI activation on the left was $-0.27(P=0.558)$. The correlation coefficient between the left halves of visual fields and fMRI activation of the right was equal to $-0.071(P=0.879)$.

Shields defines normal tension glaucoma as one of the most common forms of open-angle glaucoma ${ }^{35}$. We do not share this view; we feel that these are two separate etiopathogenetic diagnostic groups.

This finding led us to another assumption: First, if HTG causes damage of cells in the visual cortex, then similar or greater changes must occur during the yellow/ blue checkerboard stimulation as well, and vice versa. Second, if in the NTG no fMRI changes after the black/ white pattern occur, then no changes in fMRI activity should occur even after the stimulation with yellow/blue pattern.

It has been known since 1883 (ref. ${ }^{36}$ ) that in HTG, in addition to visual field changes, disorder of colour perception can be found. It is confirmed by more recent studies that specify the disorder of colour perception in HTG, mainly in the yellow/blue part of the spectrum ${ }^{37-40}$. With progressing stage of glaucoma the disorder of colour perception progressed as well ${ }^{40-43}$. In experimentally induced HTG, pathology of both parvo- and magnocellular and coniocellular pathways is known ${ }^{30}$. It cannot be said that some of the cells constituting these pathways are spared by the glaucoma disease. It is the ganglion cells that are the last ones in the retina encoding colour signals.

It is not necessary to discuss here the physiology of colour processing of the input from photoreceptors to the visual cortex. An important fact is the existence of the pathology in HTG.

Therefore, the disorder of colour perception can be explained by the impairment or loss of ganglion cells, which are involved in the processing of colour stimuli. How do the $\mathrm{L}, \mathrm{M}$ and $\mathrm{S}$ retinal cones influence the development of colour vision disorder in HTG remains unclear. Nork's study ${ }^{44}$ demonstrated that in HTG, disorder on the level of cones can exist as well, and he proved the oedemas of the $\mathrm{L} / \mathrm{M}$ cones in experimental animals similar to those seen in human glaucoma retinas. However, he has not noticed any loss of cones. Greenstein et al. ${ }^{45}$ have shown in experimental high tension glaucoma in monkeys that changes in early glaucoma damage especially the S pathways. $\mathrm{L}$ and $\mathrm{M}$ pathways are affected in the process of more advanced stages of the disease.

We have used yellow/blue matrix to stimulate the channels processing the colour stimuli, and compared the resulting BOLD activations with the black/white structured stimulation. The yellow/blue colours have been chosen deliberately. All the three opponent colours were included (red-green, by mixing of which yellow and yellowblue colours arise). From our results we can see that the visual cortex is damaged by glaucoma progress more than it seems at the stimulation by black/white patterns.

There are only few studies about the test of colour vision perception. Lachenmayer and Drance ${ }^{46}$ have tested visual functions in HTG and NTG, and have found that HTG (intraocular pressure $>$ or $=30 \mathrm{mmHg}$ ) shows highly statistically significant correlations between the low- and high-frequency ends of the foveal temporal contrast sensitivity function and foveal and parafoveal blue-on-yellowsensitivity and the global field indices, whereas in the normal tension glaucoma subgroup no significant correlations were found. The results of the presented study support the idea that there are two different mechanisms of glaucomatous damage, one of which is pressure-dependent and one which may be pressure-independent. The pressure-dependent mechanism is responsible for deficits of central or paracentral function which are correlated to overall visual field damage.

Budde et al. ${ }^{41}$ tested colour perception using the Farnsworth Munsell 100-hue test and found no difference between HTG and NTG (ref. ${ }^{40}$ ). Polish authors ${ }^{41}$ discovered colour perception disorder in $57 \%$ of eyes with glaucoma (both HTG and NTG ones). At the same time they found a positive correlation between impaired colour vision and visual field changes.

Yamagata et al. ${ }^{47}$ found that in normal tension glaucoma, the incidence of yellow/blue abnormalities in visual field test was only in $11 \%$, compared to $52 \%$ in high tension open-angle glaucoma, the mean deviation being the same for both of them. From this brief overview it follows that colour perception test findings in normal tension glaucoma are not quite clear. 
To investigate colour perception in our patients, we used the Lanthony 15-Hue test. We have not found colour perception disorder in any of them. During the test with the Ishihara test we found the fault in resolution of number 74 in two patients. We know that these tests do not give such results as the anomaloscope examinations, but this was not our primary goal. We wanted to demonstrate that the visual cortex in normal tension glaucoma behaves differently than in high tension ones. To eliminate some error in possible colour perception disorder, we chose for investigation a group of patients with various visual field changes (pattern defect 01.12 - 12.65).

No information of using coloured stimuli for fMRI examinations is available in literature so far. We used yellow/blue matrix to stimulate the channels processing the colour stimuli, and compared the results of BOLD activations with the black/white structured stimulation.

We demonstrate with our results that the visual cortex is behaving in normal tension glaucoma similarly as after stimulation by black/white patterns. Both pieces of information show the difference of damage in normal tension glaucoma from high tension glaucoma.

In patients with NTG no corresponding functional changes in the cerebral cortex occur in contrast to HTG, where, with the glaucoma progressing changes, decrease in the activation of the visual cortex occurred. We assume that normal tension glaucoma behaves pathogenetically in a different way than the high tension glaucoma.

\section{CONCLUSION}

Despite new technology problems of HTG remain unsolved. Even greater lack of knowledge is at the NTG. In our survey, we have tried to uncover the so far relatively unknown condition in the visual cortex of human glaucoma. In HTG we have proved damage to the entire visual pathway from retinal ganglion cells up to the visual cortex. In NTG the retinal cell structures and those of visual cortex are relatively intact.

\section{ABBREVIATIONS}

BW, Black/white; LGN, Laterale geniculate nucleus; CNS, Central nervous system; C/D, Cup/disc ratio; FDG, Fluorodeoxyglucose; fMRI, Functional magnetic resonance imaging; HH VF, Homolateral halves of visual field; HTG, High tension glaucoma; Hz, Hertz; IOP intra ocular pressure; NTG, Normal tension glaucoma; PET, Positron emission tomography; PSD, Pattern standard deviation; RE, Right eye; LE, Left eye; VA, Visual acuity; FWHM, Full-width at half-maximum; YB, Yellow/blue.

\section{CONFLICT OF INTEREST STATEMENT}

The authors stated that there are no conflicts of interest regarding the publication of this article.

\section{REFERENCES}

1. Araie M, Yamagami J, Suziki Y. Visual field defects in normal-tension and high-tension glaucoma. Ophthalmology 1993;100:1808-14.

2. Lester M, De Feo F, Douglas GR. Visual field loss morphology in highand normal-tension glaucoma. J Ophthalmol 2012; 327326. Epub 2012:Feb 8.

3. Thonginnetra O, Greenstein VC, Chu D, Liebmann JM, Ritch R, Hood DC. Normal versus high tension glaucoma: a comparison of functional and structural defects. J Glaucoma 2010;19(3):151-7.

4. Shin IH, Kang SY, Hong S, Kim SK, Seong GJ, Ma KT, Kim CY. Comparison of OCT and HRT findings among normal tension glaucoma, and high tension glaucoma. Korean J Ophthalmol 2008; 22(4):236-41.

5. Eid TE, Spaeth GL, Moster MR, Augburger JJ. Quantitative differences between the optic nerve head and peripapillary retina in low-tension glaucoma and high-tension primary open-angle glaucoma. Am J Ophthalmol 1997;124(6):805-13.

6. Park HY, Jeon SH, Park CK. Enhanced depth imaging detects lamina cribrosa thickness differences in normal tension glaucoma and primary open-angle glaucoma. Ophthalmology 2012;119(1);10-20.

7. Flammer J, Prünte C. Ocular vasospasm. 1: Functional circulatory disorders in the visual system, a working hypothesis. Klin Monbl Augenheilkd 1991;198(5):411-2.

8. Okuno T, Sugiyama T, Kojima S, Nakajima M, Ikeda T. Diurnal variation in microcirculation of ocular fundus and visual field change in normal-tension glaucoma. Eye (Lon) 2004;18(7):697-702.

9. Plange N, Remky A, Arend O. Colour Doppler imaging and fluorescein filling defects of the optic disc in normal tension glaucoma. $\mathrm{Br}$ J Ophthalmol 2003;87(6):731-6.

10. Schwenn O, Troost R, Vogel A, Grus F, Beck S, Pfeiffer N. Ocular pulse amplitude in patients with open angle glaucoma, normal tension glaucoma, and ocular hypertension. Br J Ophthalmol 2002;86(9):9814.

11. Sung KR, Lee S, Park SB, Choi J, Kim ST, Yun SC, Kang SY, Cho JW, Kook MS. Twenty-four hour perfusion pressure fluctuation and risk of normal-tension glaucoma progression. Invest Ophthalmol Vis Sci 2009; 50(11):5266-74.

12. Chang M, Yoo C, Kim SW, Kim YY. Retinal vessel diameter, retinal nerve fiber layer thickness, and intraocular pressure in Korean patients with normal-tension glaucoma. Am J Ophthalmol 2011;151(1):100-5.

13. Cheng HC, Chan CM, Yeh SI, Yu JH, Liu DZ. The hemorrheological mechanisms in normal tension glaucoma. Curr Eye Res 2011;36(7):647-53.

14. Armaly MF, Krueger DE, Maunder L, Becker B, Hetherington J Jr, Kolker AE, Levene RZ, Maumenee AE, Pollack IP, Shaffer RN. Biostatistical Analysis of the Collaborative Glaucoma Study, I.: summary report of the risk factors for glaucomatous visual-field defects. Arch Ophthalmol 1980;98:2163-71.

15. Naskar R, Wissing M, Thanos S. Detection of Early Neuron Degeneration and Accompanying Microglial Responses in the Retina of a Rat Model of Glaucoma. Invest Ophthalmol Vis Sci 2002;43:2962-8.

16. Weber AJ, Chen H, Hubbard WC, Kaufmann PL. Experimental glaucoma and cell size, density, and number in the primate lateral geniculate nucleus. Invest Ophthalmol Vis Sci 2000;41:1370-9.

17. Yücel YH, Zhang Q, Weinreb RN, Kaufman PL, Gupta N. Atrophy of Relay Neurons in Magno- and Parvocellular Layers in the Lateral Geniculate Nucleus in Experimental Glaucoma. Invest Ophthalmol Vis Sci 2001;42:3216-22.

18. Crawford MLJ, Harwerth RS, Smith EL, Shen F, Carter-Dawson L. Glaucoma in Primates: Cytochrome Oxidase Reactivity in Parvo- and Magnocellular Pathways. Invest Ophthalmol Vis Sci 2000;41:17911802.

19. Vickers JC, Hof PR, Schumer RA, Wang RF, Podos SM, Morrison JH. Magnocellular and parvocellular visual pathways are both affected in a macaque monkey model of glaucoma. Aust N Z J Ophthalmol 1997;25(3):239-43.

20. Weber AJ, Kaufman PL, Hubbard WC. Morphology of single ganglion cells in the glaucomatous primate retina. Invest Ophthalmol Vis Sci 1998;39:2304-20.

21. Crawford ML, Harwerth RS, Smith EL 3rd, Mills S, Ewing B. Experimental Glaucoma in Primates: Changes in Cytochrome 
Oxidase Blobs in V1 Cortex. Invest Ophthalmol Vis Sci 2001;42:358 64.

22. Lestak J, Tintera J, Kyncl M, Svata Z, Obenberger J, Saifrtova A. Changes in the Visual Cortex in Patients with High-Tension Glaucoma. J Clinic Experiment Ophthalmol 2011;S:4. doi: 10.4172/2155-9570.S4-002

23. Lestak J, Tintera J, Ettler L, Nutterova E, Rozsival P. Changes in the Visual Cortex in Patients with Normotensive Glaucoma. J Clinic Experiment Ophthalmol 2012; S:4. doi: 10.4172/2155-9570.S4-008

24. Duncan RO, Sample PA, Weinreb RN, Bowd C, Zangwill LM. Retinotopic Organization of Primary Visual Cortex in Glaucoma: Comparing fMRI Measurements of Cortical Function with Visual Field Loss. Prog Retin Eye Res 2007;26(1):38-56.

25. Duncan RO, Sample PA, Weinreb RN, Bowd C, Zangwill LM. Retinotopic organization of primary visual cortex in glaucoma: a method for comparing cortical function with damage to the optic disc. Invest Ophthal Vis Sci 2007;48(2):733-44.

26. Qing G, Zhang S, Wang, B, Wang N. Functional MRI Signal Changes in Primary Visual Cortex Corresponding to the Central Norma Visual Field of Patients with Primary Open-Angle Glaucoma. Invest Ophthalmol Vis Sci 2010;51(9):4627-34

27. Gupta N, Yucel YH. Glaucoma and the brain. J Glaucoma 2001;10:289.

28. Gupta N, Yucel YH. Brain changes in glaucoma. Eur J Ophthalmol 2003; 13(S3):32-5.

29. Smith IELI, Chino YM, Harwerth RS. Retinal inputs to the monkey's lateral geniculate nucleus in experimental glaucoma. Clin Vis Sc 1993;8:113-39.

30. Yucel YH, Zhang Q, Gupta N, Kaufman PL, Weinreb RN. Loss of neurons in magnocellular and parvocellular layers of the lateral geniculate nucleus in glaucoma. Arch Ophthalmol 2000;118:378-84.

31. Yucel YH, Zhang Q, Weinreb RN, Kaufman PL, Gupta N. Effects of retinal ganglion cell loss on magno-, parvo-, koniocellular pathways in the lateral geniculate nucleus and visual cortex in glaucoma. Prog Retin Eye Res 2003;22:465-81.

32. Nguyen TH, Stievenart JL, Saucet JC, LeGargasson JF, Cohen YS, Pelegrini-Issac M, Burnod Y, Iba-Zizen MT, Cabanis EA. Cortical response to age-related macular degeneration (Part II). Functional MRI study. J Fr Ophthalmol 2004;27:72-86.

33. Baker Cl, Peli E, Knouf N, Kanwisher NG. Reorganization of visual processing in macular degeneration. J Neurosci 2005;25:614-8.
34. Lestak J, Nutterova E, Pitrova S, Krejcova H, Bartosova L, Forgacova V. High Tension Versus Normal Tension Glaucoma. A Comparison of Structural and Functional Examinations. J Clinic Experiment Ophthalmol 2012;S:5. doi: 10.4172/2155-9570.S5-006

35. Shields MB. Normal-tension glaucoma: is it different from primary open-angle glaucoma? Curr Opin Ophthalmol 2008;19(2):85-8.

36. Bull O. Bemerkungen über Farbensinn unter verschiedenen physiologischen und pathologischen Verhältnissen. Albrecht von Graefes Arch Ophthalmol 1883;29:71-116.

37. Sample PA, Weinreb RN, Boynton RM. Acquired dyschromatopsia in glaucoma. Surv Ophthalmol 1986;31:54-64.

38. Sample PA, Boynton RM, Weinreb RN. Isolating the color vision loss in primary open-angle glaucoma. Am J Ophthalmol 1988;108:686-91.

39. Drance SM, Lakowski R, Schulzer M, Douglas GR. Acquired color vision changes in glaucoma. Use of 100-hue test and Pickford anomaloscope as predictors of glaucomatous field change. Arch Ophthalmol 1981;99:829-31.

40. Jonas JB, Zäch FM. Color vision defects in chronic open angle glaucoma. Fortsch Ophthalmol 1990;87:255-9.

41. Budde WM, Jünemann A, Korth $M$. Color axis evaluation of the Farnsworth Munsell 100-hue test in primary open-angle glaucoma and normal-pressure glaucoma. Graefes Arch Clin Exp Ophthalmol 1996;234(S1):180-6.

42. Misiuk-Hojlo M, Nizankowska MH, Regiec P, Raczyńska K. Clinical advantages of colorimetric exploration in the early diagnosis of glaucomatous neuropathy. J Fr Ophthalmol 2004;27(8):891-6.

43. Papaconstantinou D, Georgalas I, Kalantzis G, Karmiris E, Koutsandrea C, Diagourtas A, Ladas I, Georgopoulos G. Acquired color vision and visual field defects in patients with ocular hypertension and early glaucoma. Clin Ophthalmol 2009;3:251-7.

44. Nork TM. Acquired color vision loss and a possible mechanism of ganglion cell death in glaucoma. Trans Am Ophthalmol Soc 2000;98:331-63.

45. Greenstein VC, Halevy D, Zaidi Q, Koenig KL, Ritch RH. Chromatic and luminance systems deficit in glaucoma. Vision Res 1996;36:621-9.

46. Lachenmayr BJ, Drance SM. Central function and visual field damage in glaucoma. Int Ophthalmol 1992;16:203-9.

47. Yamagami J, Koseki N, Araie M. Color vision deficit in normal-tension glaucoma eyes. Jpn J Ophthalmol 1995;39:384-9. 